\title{
Effects of Child Abuse on Academic Performance of Primary School Pupils in Kwande Local Government Area of Benue State, Nigeria
}

\author{
Tersoo Timothy Tsegba1, ${ }^{*}$ Ibrahim Ologele ${ }^{2}$, Kafayah Adeola Jidda ${ }^{3}$, Joseph Abiodun Stephen ${ }^{4}$ \\ 1,2,3 Department of Health Promotion and Environmental Health Education, Faculty of Education \\ University of Ilorin, Nigeria \\ 4, College of Science and Information Technology, Department of HKHE, Tai Solarin University of Education
}

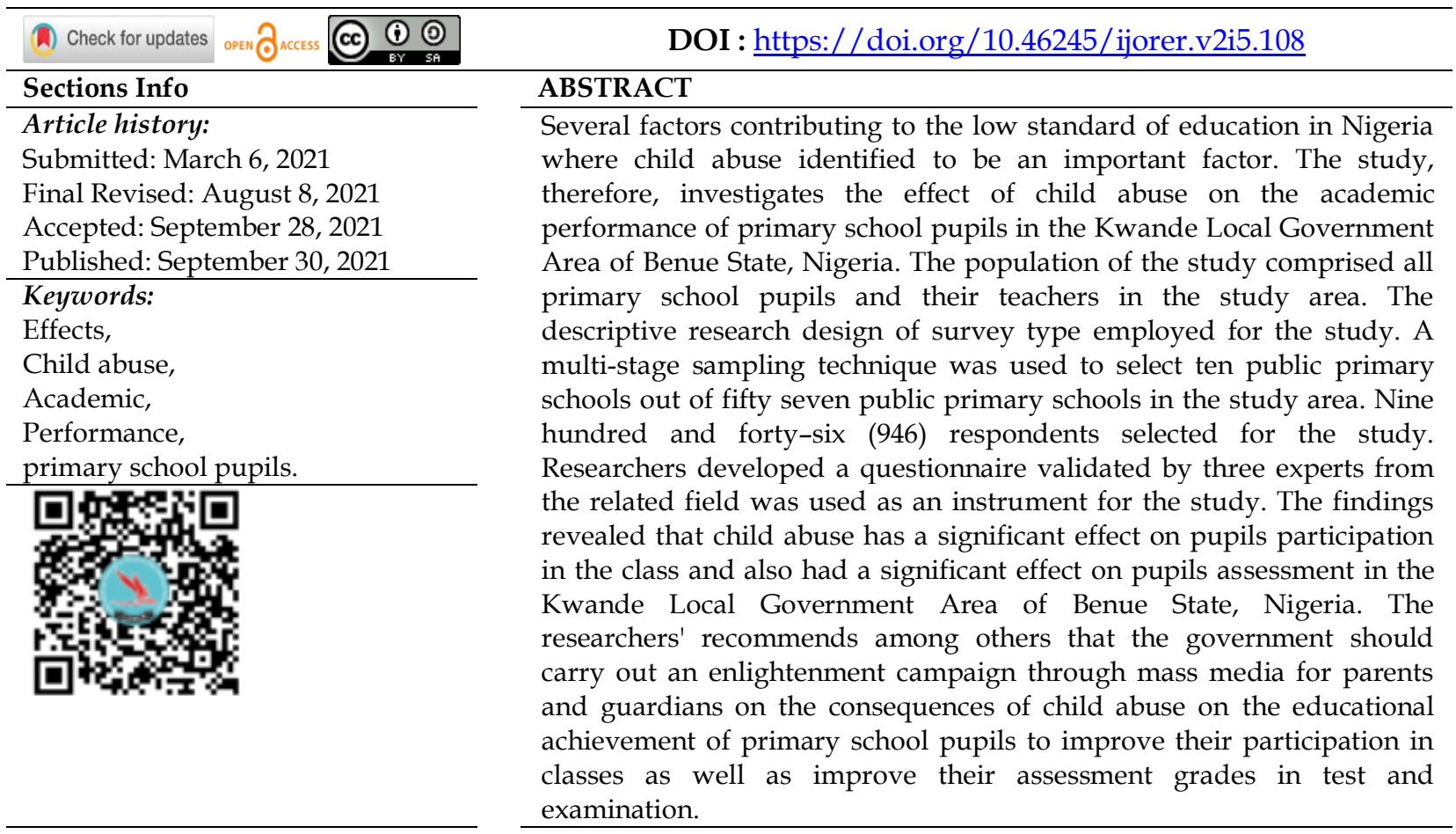

\section{INTRODUCTION}

Globally, childhood is regarded as a period of sensitivity requiring special attention, care and protection. In the traditional African context, children were not allowed to listen to adults' conversations let alone, make comment or contributions. The problem of child abuse has long been existing in Nigeria and has even become more even devastating to the society as a whole (Life learners, 2018). Child abuse (also referred to as child maltreatment) encompasses all methods physical, sexual or emotional harsh treatment, or any form of neglect that causes actual or prospective harm to the child's health, development, or self-worth (Al Odhayani et al., 2013). Child abuse is one of the most challenging social catastrophes attracting public attention the world over (Alokan and Olatunji, 2014). (Augustin and Abubaker, 2016) lamented that there is no safe place for children anymore because child abuse is rampant everywhere. (Ada and Anake, 2015) opined that child abuse is an act of inflicting serious, physical injury and emotional torture on a child or person, which is intentional or unintentional and could endanger the physical, health, emotional, social, moral and educational wellness of the child. The contributing factor of child abuse can be identified as poverty and ignorance on the part of the parents or guardians and others. 
Effects of Child Abuse on Academic Performance of Primary School Pupils in Kwande Local Government Area of Benue State, Nigeria

Child abuse has been defined by the International Child Abuse Network as "the bad treatment of a child under the age of 18 by a parent, caretaker, someone living in their home, or someone who works with or around children". When an adult abuses a child, it shows instability and irresponsibility in an effort to demonstrate dominance over a minor in order to gain power - an adult taking advantage of the innocence, naivety, and weakness of a child. Within the general definition of child abuse, there are four types of child abuse: physical, emotional, sexual, and neglect (International Child Abuse Network, 2012).

Broadly defined, child abuse is when a parent, a primary caregiver, or any other person who has responsibility for the child through an action (e.g., beating, stabbing) causes injury, death, emotional harm, or risk of serious harm to a child. Child abuse can take many forms including physical abuse, sexual abuse, exploitation, and emotional abuse (Altafim and Linhares, 2016). Existing research indicates that emotional abuse is the most common form of abuse (Foster et al., 2017) with physical abuse being the most reported (Tillman et al., 2015) and sexual abuse being the least reported (Foster et al., 2017). Conversely, child neglect is defined as the failure of a parent, guardian, or other caregiver to provide for a child's basic needs (e.g., physical, medical, educational, and emotional needs). According to (Foster et al, 2017), child neglect is often underreported but has devastating effects on children. Child maltreatment consists of child abuse and child neglect. (Usakli, 2012) noted that child maltreatment "occurs across socioeconomic, religious, cultural, racial, and ethnic groups". It is estimated that approximately $80 \%$ of child maltreatment is perpetrated by parents or primary caregivers, except for sexual abuse which in most cases is perpetrated by acquaintances or other relatives.

Child abuse is a global problem that needs to be tackle if children are to be given the right to education and freedom. UNICEF opined that the Nigerian child right act bill was passed into law in July 2003; the bill received the assent of then-president of the Federal Republic of Nigeria, Chief Olusegun Obasanjo, in September 2003 and was promulgated as the child rights act 2003. The report showed that there is a lack of enforcement of the act by lawmakers and the judiciary.

Child abuse has become a worldwide problem and it has been established that many children in the developed countries such as American are abusing their children and the problem extending to some Africa countries such as South Africa, Nigeria and Kenya. (Wafaa and Wejdan, 2017) opined that one of the major worldwide health issues affecting children is child maltreatment. The problem causes both immediate and lifelong physical and mental impairment. Poor school performance and educational achievement are among the consequences of child abuse and neglect. Physical abuse was predicted to negatively affect children's academic and behavioural adjustment through the creation of deficits in academic engagement, social competencies, ego resilience, and ego control. Maltreated children having lower grades, more suspension, more grades repetition, show less academic achievement, more social skills deficits and lower ego resilience than non-maltreated children. Individual academic performance levels are affected by a host of factors outside of the classroom. Children who lived in a positive home enriched their school experienced and those who lived-in a negative home environment can have a detrimental impact on both students academic performance and their classroom behaviour. Children who have been abused and 
neglected tend to score lower than the general population on measures of cognitive capacity, language development and academic achievement.

Frasisca argued that parents or guardians who have a strong relationship with their children may not abuse their children while those with weak relationships tend to abuse their children. Strong relationships make children rely on their parent when they need help which enhances the academic performance of children. Poor relationship of parents with children which usually caused due to child abuse may make children not to seek help from their parents because of fear. Consequently, such children are unlikely to perform well on their academic programme when compared to their peers with parental support.

(Theoklitou et al., 2012) pointed out that physical abuse is the deliberate infliction of serious injuries or actions that place the child at obvious risk of serious injury or death, to be illegal - bruises, scratches, burns, broken bones, lacerations, as well as reported "mishaps' and rough treatment that could cause physical injury. It could also affect the child academic performance and interest. (Ada and Anake, 2015) explained that the increasing number of students and pupils and those out of school hawking and selling goods around the streets and school premises in some rural areas and towns is alarming. Some of the children look so malnourished and sick, others in pain of being hurt by beatings and assaulted by gangsters. Some of these children are sent out there by their parents or caregivers, the interest of most parents is what the child can bring to the home through sells (hawking goods) or giving oneself for money; many leave school as early as primary school, age 12 to engage in prostitution while others are used as house helps and other menial jobs to bring in money to the family. As a result the moral and social development of the child has no education base; their performance in school is affected. The child is therefore a tool for profit making.

Physical and psychological abuses are often linked to negative effects on mental and physical health. For example, it has been documented that anxiety and depression tend to arise more frequently among children who are abused. Expose of children to toxic stress in the early years can undermine lifelong health, learning and behaviour, because the hormones associated with the fight-or-flight response, such as cortisol can inhibit physical growth and the children's susceptibility to illness. It is also the case that these hormones can impair the development of neutral connections in parts of the brain that are critical for learning (Esteban, 2017).

Unfortunately, it is a largely accepted fact that abused and neglected children are at higher risk for lower academic achievement. Additionally, studies show that children who have suffered from neglect exhibit lower academic achievement children who were physically abused. Mistreated children have a greater instance of exhibiting poor social skills and classroom behavior problems. Maltreatment in the first five years of life nearly triples a child's likelihood of having academic problems. These children are far likelier to drop out of school before completing high school. According to research, children with special educational needs are more than seven times more likely to suffer physical abuse and neglect. Lower academic success can cause lifelong, negative psychosocial and economic consequences. In sexually abused children, cognitive ability and memory scores as well as academic achievement are lower than their peers. Most people do not realize that child sexual abuse is one of the most significant risks facing children today. One in ten children is the victim of sexual abuse. A study of sexually abused 7-12 year-old girls showed: 39\% displayed academic difficulties, 24\% repeated a 
grade, $15 \%$ were enrolled in a remedial class, $48 \%$ reported below average grades, and over $37 \%$ displayed cognitive ability below 25\% (CASA, 2015).

(Alokan and Olatunji, 2014) pointed out that success within the academic environment is an important value instilled during childhood. Children who are able to gain academic success within their school years are more likely to have an overall sense of wellbeing throughout childhood and into adulthood. Although it may be ideal for all children to perform well within the school environment, there are many outside factors that can hinder a child's potential for academic success. Recent development in the society, coupled with economic realities, influence of parents' behaviour and attitudes towards their children. Hardship forces parents to solicit for the assistance of their children in the trade in order to improve the socio-economic viability of the home. Poverty is one of the psychosocial determinants of child/abuse including child labour which could have a far-reaching effect on academic performance. It appears that there is a continuous decrease in children's interest in school activities resulting in flagrant disobedience to school rules and regulations such as truancy, absenteeism and even school drop-out. Failure of both internal and external examination has also reached a disturbing rate. Negative health outcomes related to child maltreatment such as neglect, hunger and all forms of abuse (sexual, physical and emotional) including child labour are strong indicators of poor academic performance. Children who are maltreated are less attentive and engaged in school, have higher absenteeism, lower grades, lower test scores, and are more likely to drop out of school than children who are not maltreated.

It has been observed that the academic performance of children in public primary schools in the Kwande Local government Area of Benue State is becoming low. One wonders if such low academic performance is a result of the maltreatment children are exposed to. The study, therefore, seeks to find out if child abuse has any effect on the academic performance of primary school pupils. Especially, the big question is; does physical, emotional and sexual abuse affects the academic performance of primary school pupils? The major objective of the study is to determine the effect of child abuse on the academic performance of primary school pupils in the Kwande Local Government Area of Benue State.

\section{Statement of the Problem}

Despite the signing of the documents on child rights and the convention for the elimination of all forms of discrimination against women by Nigeria, yet, violation of the child right, child abuse and discrimination against women continued in Nigeria. Child abuse is a serious public health problem and occurs in varying proportions or magnitudes, resulting in a burden imposed on children by parents or adults. Most adults often impose their wishes on children without any recourse to their feelings. This flagrant imposition more often than not instilled so much fear in the minds of children. Children are faced with devastating consequences of child abuse in the homes, school and society in general.

Some children in the study area were given activities to do at home by their parents or guardians where some of the activities may beyond the pupils capacity and some may even hawk early in the morning before preparing for school. Some pupils become less active in the class due to using some of their energy on home activities or morning hawking before going to school and some continue hawking immediately they came back from school. Consequently, the home activities and hawking designed for some pupils in the study area by their parents or guardians put them at risk of a road 
accident, sexual abuse and also responsible for their low performance on their academic programme.

At the heart of every educational system lays the desire for the students, teachers and the institutions to achieve their educational goals; however, the extent to which this desire is achieved in the study period of a student varies based on individual differences. Individual differences in academic performance have been linked to differences in intelligence and personality. Students with higher mental ability as demonstrated by IQ tests and those who are higher in conscientiousness (linked to effort and achievement motivation) tend to perform highly in academic settings. A recent meta-analysis suggested that mental curiosity (as measured by typical intellectual engagement) has an important influence on academic performance in addition to intelligence and conscientiousness.

Despite high mental abilities, conscientiousness and intellectual engagement demonstrated by some children, it has been observed that the academic performance of children in public primary schools in the State, particularly, in the Kwande Local Government Area is becoming low due to the problem of child abuse. This became the motivation to investigate the effect of child abuse on the academic performance of primary school pupils in Kwande Local Government.

\section{Research Hypotheses}

The following hypotheses are hereby projected;

HO 1: Child abuse has no significant effect on pupils' participation in the class among primary school pupils in Kwande local government area of Benue State, Nigeria

HO 2: Child abuse has no significant effect on pupils' assessments grades among primary school pupils in Kwande local government area of Benue State, Nigeria.

\section{RESEARCH METHOD \\ Sample and Population}

A descriptive research design of survey type was employed for the study. The population of the study comprised all primary school pupils and their teachers in the study area. Multi-stage sampling technique was used to select the samples used for the study which consisted of Nine hundred and forty - six (946) subjects, made up of one hundred (100) teachers and eight hundred and forty - six (846) pupils were selected from ten public primary schools used for the study out of fifty seven public primary schools in the study area. Opined that population include all members from a specified group, all possible outcomes or measurements that are of interest. The exact population will depend on the scope of the study. A sample consists of some observations drawn from the population, so a part or a subset of the population. The sample is the group of elements who actually participated in the study.

\section{Instrument and Procedure}

Two instruments developed for the study titled "child abuse and Academic performance Questionnaire were used for both teachers and pupils selected as respondents for the study. Method of scoring was done using the Likert rating scale method of strongly Agree (4), Agree (3), Disagree (2) and Strongly Disagree (1). Both the construct, face and content validity of the instrument used for the study were ascertained by experts from the relevant fields. The split-half method was used to ascertain the reliability of the instrument while the result of 0.92 was obtained through 
the use of the Cronbach Alpha coefficient. The researchers administered the instrument to the respondents. The frequency count and the percentage used to analyse demographic data while a one-sample t-test was used to analyse the result of stated hypotheses at 0.05 level of significance. The steps used for research procedure can be seen in figure 1.

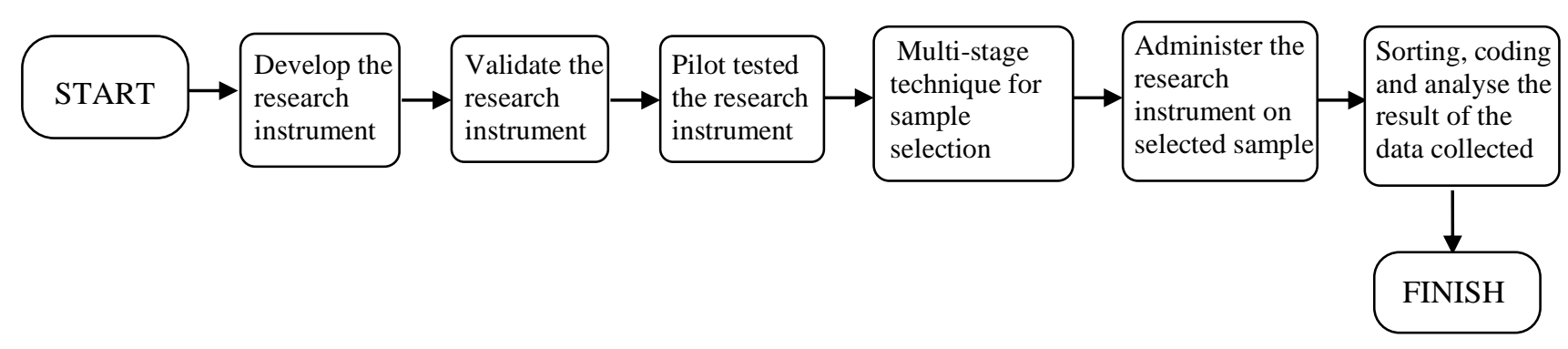

Figure 1: The flow chart showed the research procedure.

The researchers developed questionnaire was used as an instrument for the study. The data received from the quantitative instrument used for the study subjected to analysis and result obtained from the procedure become information. (Daniel, 2020) pointed out that a questionnaire is a research device or instrument that is made up of a series of questions which are closed-ended or open-ended. The goal is to collect relevant data from respondents which can then be used for a variety of purposes. When you give the respondent the ability to give a longer answer, it can yield more insights because they can elaborate on their thoughts. Also, (Aashish, 2019) explained that a questionnaire is a research instrument consisting of a set of standardized questions to gather statistically useful information on some subject from one or more respondents.

\section{RESULTS AND DISCUSSION}

The results obtained from the two hypotheses used for the study were shown in the tables:

$\mathbf{H O}_{1}$ : Child abuse has no significant effect on pupils' participation in the class among primary school pupils in Kwande local government area of Benue State, Nigeria

Table 1: One sample t-test on the effects of child abuse on pupils' participation in the class.

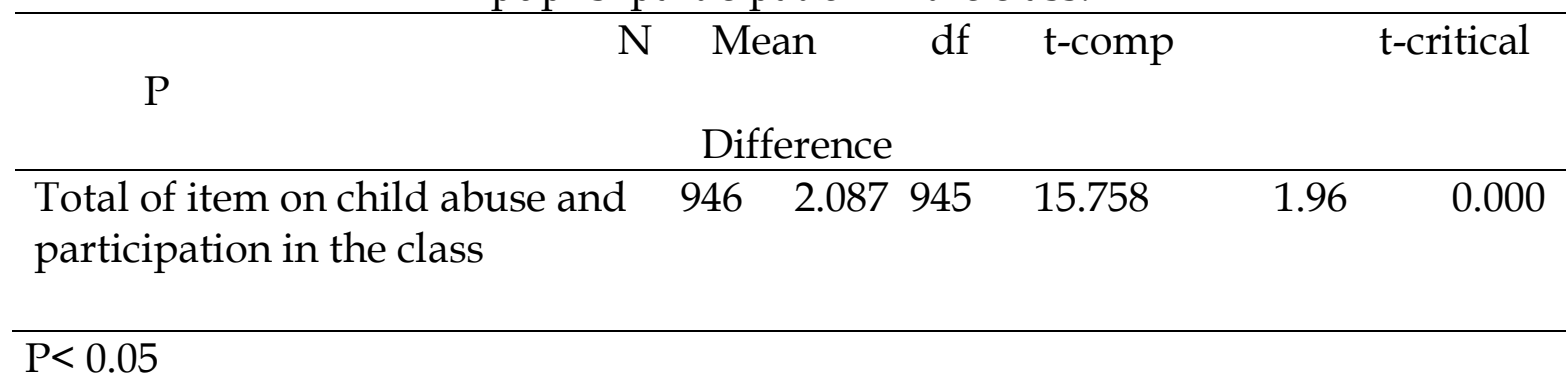

The outcome of the one-sample t-test statistics in table 1 above showed that child abuse has a significant effect on pupils participation in the class among primary school pupils in the Kwande local government area of Benue State, Nigeria. The reasons being that the calculated P-value of 0.000 is less than 0.05 level of significance and the computed t-value of 15.758 is greater than the critical t-value of 1.96 at 945 degrees of 
freedom. Therefore, the null hypothesis which states that child abuse has no significant effect on pupils' participation in the class is rejected and the alternative hypothesis upheld that child abuse has significant effects on pupils participation in the class among primary school pupils in the Kwande local government area of Benue State, Nigeria.

$\mathbf{H O}_{2}$ : Child abuse has no significant effect on pupils' assessments grades among primary school pupils in Kwande local government area of Benue State, Nigeria

Table 2: One sample t-test on the effects of child abuse on pupils' assessment grades.

\begin{tabular}{ccccc}
\multicolumn{6}{c}{ abuse on pupils assessment grades. } \\
\hline critical & $P$ & $N$ & Mean & t-comp t-
\end{tabular}

Difference

$\begin{array}{llllll}\text { Total of item on child abuse and } & 946 & 2.036 & 945 & 50.255 & 1.96 \\ 0.000 & & & & \end{array}$

Assessment of grades

$\mathrm{P}<0.05$

The outcome of one sample t-test statistics on table 2 showed that child abuse has a significant effect on pupils' assessment grades among primary school pupils in the Kwande local government area of Benue State, Nigeria. The reason for this is that the calculated P-value of 0.000 is lower than 0.05 level of significance and the computed $t-$ value of 50.255 greater than the critical $t$-value of 1.96 with a 945 degree of freedom. Therefore, the null hypothesis which states that child abuse has no significant effect on pupils' assessment grades and academic performance is rejected and the alternative hypothesis accepted that child abuse has a significant effect on pupils' assessment grades among primary school pupils in Kwande local government area of Benue State, Nigeria

\section{Discussion of Findings}

The result of the first hypothesis tested showed that child abuse has a significant effect on pupils' participation in the class in the Kwande local government area of Benue State. The result of the finding carved around the fact that a child who is maltreated tends to think a lot and have his attention drifted away from the work at school. When a child is abused, he/she would find it difficult to concentrate in class and the child's level of assimilation would be affected, thus finding it hard to understand whatever he/she is being taught. This would make the child a passive listener and also a passive participant in the class which would culminate in poor academic performance. The result of the finding is in line with the result of a study carried out by (Alokan and Olatunji, 2014) conducted a study on the influence of child abuse on classroom behaviour and academic performance among primary and secondary school learners in the Etiki State of Nigeria. All teachers in primary and secondary schools in both public and private sectors in Ado local government area of Ekiti State in Nigeria were targeted for the study. The study found out that there is a significant relationship between children's active involvement in parents' business and their attitude to class work. Abused students tend to have less concentration span in class. In schools, these 
symptoms manifest themselves through students' inability to concentrate, complete school work in time, or understand schoolwork; being fearful, frustrated, stupid or bad about themselves; achieving low grades; and or being told they are lazy or slow.

The result of the second hypothesis tested for the study revealed that child abuse has a significant effect on pupils' assessment grades in the Kwande local government area of Benue State. The result of this finding carved around the fact that a child who is maltreated suffers from emotional trauma lost will power and a feeling of inferiority which makes his/her mental strength weak. This finding agrees with the result of the study conducted by (Ligeve and Poipoi, 2012) among 333 pupils from two districts in Kenya. The result of the study revealed that there is a significant difference in the academic achievement of pupils who were involved and those who were not involved in fishing activities and that the academic achievement of boys not involved was significantly higher than that of girls involved in fishing activities. Also, the result of a study conducted by (Mfonobong, 2013) on 200 primary and secondary schools in Eastern Nigeria. The study concludes that child abuse and neglect is a global problem that takes place in many setting one of which is the school, and it has serious implications on the educational system in Nigeria. It makes the students perform badly in both internally and externally administered examinations thus presenting a serious drawback on the child educational development by hindering societal growth and development. More so, the result of the study conducted by (Sylvia and Davison, 2017) among primary schools pupils in the Manzimi region of Swaziland. Four primary schools jn Manzini region were selected for the study. Both the abused learners and their teachers were selected for the study. The findings revealed that most $(47 \%)$ of the learners experienced physical abuse and only (20\%) experienced emotional and verbal abuse whilst a minority of (13\%) experienced sexual abuse. The findings of the study indicated that $(65 \%)$ of the learners scored low in their tests, class work and in examinations due to abuse. In addition to that, the findings further indicated that $25 \%$ of the learners were not affected academically as they stated that they score high marks in the tests and examinations. However, some of the class teachers of the abused learners reported that the academic performance of the abused learners is affected because the learners begin to pay less attention to school work. They pay attention to the painful experiences of abuse. Hence, they neglect assignments and do not put maximum effort when writing tests. They also reported to have observed that abused learners are not doing well and repeat grades. Some abused learners always absent themselves and thus dropping in their academic performance. Some teachers indicated that the performance of abused learners is dropping drastically and the abused learners cannot be free. They were reported not to be participating well in class discussions and do not respond promptly when asked questions and one can tell that they minds are paying attention to something else. The study also revealed that cases of abuse in the primary schools are well known yet very little is done. The teacher participants in this study reported that the experiences of abused learners have led to loss of concentration in class. The result was that many of the abused learners lag behind in their school work. The study also showed that abuse among the survivors was also responsible for poor classroom participation. Thus, $70 \%$ of the abused learners indicated that they failed to concentrate in class due to the experiences of abuse which always crosses their minds and haunts them. The findings showed that majority of the abused learners underperformed as a result of abuse and became suspicious of every person around them and this had a negative bearing to their academic performance. Some became anti- 
social land adopted a misdirected rancorous attitude to everyone around them. Thus in the main, the study concludes that child abuse affects the academic performance of learners at primary school level.

\section{CONCLUSIONS}

The implication of the findings revealed that pupils experience child abused are less attentive in the class activities, have higher number of absenteeism, experience lower grades on test and examination. Some of the abused pupils prefer to drop out of the school. This research is only limited to public primary school pupils and primary school pupils in the private schools in the study area not included. It is necessary to have a broader future research to carry out the same topic on both public and private primary school pupils in the Kwande local government area of Benue State so that it can support and strengthen this research study. The government should carry out an enlightenment campaign through mass media for parents and guardians on the consequences of child abuse for the educational achievement of primary school pupils to improve their participation in classes as well as improve their assessment grades in test and examination. Intense awareness should be created among teachers and school managers using seminars, workshop and training programs about what constitutes child abuse. As much as possible, teachers/caregivers should avoid the use of corporal punishment because it only teaches children that violence is the best way of maintaining control and it encourages them to hit other children.

\section{REFERENCES}

Aashish, P. (2019). Questionnaire: Definition, types, examples $\mathcal{E}$ how to design. Fredough

Ada, P. A., \& Anake, P. M. (2015). Child abuse and students academic performance in boki local government area of cross river state. British Journal of Education, 3(3), 34-42.

Al Odhayani, A., Watson, W. J., \& Watson, L. (2013). Behavioural consequences of child abuse. Canadian Family Physician, 59(8), 831-836.

Alokan, F. B., \& Olatunji, I. C. (2014). Influence of child abuse on classroom behaviours and academic performance among primary and secondary school students. European Scientific Journal, 10(10), 131-140.

Altafim, E. R. P., \& Linhares, M. B. M. (2016). Universal violence and child maltreatment prevention programs for parents: A systematic review. Psychosocial Intervention, 25(1), 27-38.

Augustin, S. A., \& Abubaker, I. S. (2016). The effects of child abuse on the academic of school children: Implication on the Nigerian economy. Asia Pacific Journal of Education, Arts and Science, 3(3), 23-27.

CASA. (2015). How child abuse affects academic achievement?. Casa Child Advocates Of Montgomery County. https://casaspeaks4kids.com/child-abuse-affectsacademic-achievement/

Daniel, N. (2020). Questionnaire, types, definition, examples and how to design your own. Keyleads Company. https://www.kyleads.com/blog/questionnaire/

Esteban, O. (2017). Child maltreatment and educational outcomes. Our World in Data. https://ourworldindata.org/child-maltreatment-and-educational-outcomes.

Foster, R. H., Olson-Dorff, D., Reiland, H. M., \& Budzak-Garza, A. (2017). Commitment, confidence, and concerns: Assessing health care professionals' child maltreatment reporting attitudes. Journal of Child Abuse and Neglect, 67(3), 54-63.

International Child Abuse Network. (2012). Child Abuse Defined. http://www.yesican.org/defined.html 
Life learners. (2018). Effects of child abuse on students' academic performance. Nigeria: Life Learners. https://lifelearners.ng/effects-of-child-abuse-on-students-academic-performance/

Ligeve, S. N., \& Poipoi, M. W. (2012). The influence of child labour on academic achievement of primary school pupils in Suba and Homa-Bay Districts, Kenya. International Journal of Learning $\mathcal{E}$ Development, 2(4), 43-55. https:// doi.org/10.5296/ijld.v2i4.2214

Mfonobong, E. U. (2013). Child abuse and its implications for the educational sector in Nigeria. Child Maltreatment, 2(2), 12-24.

Sylvia, L. D., \& Davison, M. (2017) Effects of Child Abuse on the Academic Performance of Primary School Learners in the Manzini Region, Swaziland. World Journal of Education, 7(5), 56-65.

Theoklitou, D., Kabitsis, N., \& Kabitsi. (2012). Physical and emotional abuse of primary school $\begin{array}{llll}\text { children by teachers. Child abuse Neg, 26(1), 64-70. } & \end{array}$ https:// doi.org/10.1016/j.chiabu.2011.05.007.PMID22197151

Tillman, K. S., Prazak, M. D., Burrier, L., Miller, S., Benezra, M., \& Lynch, L. (2015). Factors influencing school counselors' suspecting and reporting of childhood physical abuse: Investigating child, parent, school, and abuse characteristics. Professional School Counseling, 19(1), 103-115. https:/ / doi.org/10/5330/1096-2409-19.1.103

United Nations Children's Fund. (2012). The state of the world's children 2012: children in an urban world. New York, USA.

Usakli, H. (2012). School help professionals' ideas on child abuse and neglect. Journal of Educational Sciences and Psychology, 54(2), 115-124.

Wafaa, E., \& Wejdan, S. (2017) Effect of physical abuse on academic achievement among secondary school female students in Jeddah. Journal of community and public health nursing, $3(2), 1-7$.

\footnotetext{
* Tersoo Timothy Tsegba

University of Ilorin, Nigeria

Department of Health Promotion and Environmental Health Education, Faculty of Education,

Email: tsergbatersootimothy@gmail.com

Ibrahim Ologele (PhD) (Corresponding Author)

University of Ilorin, Nigeria

Department of Health Promotion and Environmental Health Education, Faculty of Education,

Email: ologele2010@gmail.com

Kafayah Adeola Jidda (PhD)

University of Ilorin, Nigeria

Department of Health Promotion and Environmental Health Education, Faculty of Education,

Email: kafayahjidda@yahoo.com

Joseph Abiodun Stephen (PhD)

Tai Solarin University of Education

College of Science and Information Technology, Department of HKH Ijagun, Ijebu-Ode

Email: stephenabiodun123@gmail.co
} 